\title{
Geochemistry of the Maastrichtian Rørdal Member, Jylland, Denmark: Ce anomaly as a palaeo-redox proxy
}

\author{
Christian Knudsen and Bodil W. Lauridsen
}

The chemical composition of chalk and marl reflects the mixture of carbonate particles and clastic input deposited on the seabed together with growth of authigenic minerals and diagenesis. The Rørdal quarry in Jylland (Fig. 1) is known for its alternating chalk-marl succession (Surlyk et al. 2010) and the aim of this article is to investigate how this cyclicity is reflected in the geochemical signature of the sequence and test if this has implications for the interpretation of the depositional environment as well as the chemostratigraphy in the chalk.

The observed variation in the benthic fauna and the cyclic character of the chalk-marl succession may reflect an environmental response to orbital forcing. The benthic fauna shows higher species diversity and density in the chalk than the marl layers, suggesting more favourable living conditions in the former (Lauridsen \& Surlyk 2008), whereas no differences in environmental stress between the two environments could be derived from a study of the trace fossils (Lauridsen et al. 2011).

The c. $10 \mathrm{~m}$ thick Rørdal Member was established as a lithostratigraphic unit by Surlyk et al. (2010) and recognised as an expression of a late Maastrichtian cooling event. X-ray diffraction (XRD) analysis indicates that the marly layers represent a relative increase in smectite clays and illite together with some quartz and analcime. The inorganic geochemical evolution in Maastrichtian chalk was investigated by Jørgensen (1986) who noted changes in Sr/Ca and $\mathrm{Mn} / \mathrm{Ca}$ ratios towards the end of the Maastrichtian in the North Sea Central Graben, leading to the conclusion that geochemistry is a "conceivable tool in basin analysis in the lithologically rather monotonous chalk sequence" (p. 267). However, a systematic geochemical analysis of the chalk has never been undertaken and this work is an attempt to look into the potential of understanding the geology of the chalk by analysing a wide range of elements in chalk and marl.

\section{Chemical variability related to clay content}

Sixty-three samples from the Rørdal quarry were ground, digested in aqua regia and analysed for 66 elements using the Elan 6100 Quadrupole ICP-MS at the Geological Sur- vey of Denmark and Greenland (GEUS). The data reduction was based on TotalQuant software with emphasis on the trace element analysis. The analytical procedure follows Larsen et al. (2009).

The cyclicity and the alternation between chalk and marl are easily recognised in the geochemical profile (Fig. 2) with an increase in the concentration of major and minor elements such as $\mathrm{Al}, \mathrm{Si}, \mathrm{Fe}, \mathrm{Mg}$ and $\mathrm{K}$ in the marly layers caused by the presence of clay. The eight peaks in Fig. 2 can be correlated to the eight peaks in the marly layers of the Rørdal Member which can be identified in the gamma log in a nearby well (Surlyk et al. 2010). The gamma-radiation in the well $\log$ can be explained by the increased content of $\mathrm{K}$ in the marl (Fig. 2A). Iron is the element after $\mathrm{Al}$ with the highest increase in concentration in the marly layers indicating that the clay minerals are rich in Fe. Magnesium also shows an increase in the marly layers (Fig. 2A), and the combined clay minerals in the marl - which according to Surlyk et al. (2010) consist of smectite and illite - must be rich in $\mathrm{Fe}, \mathrm{K}$ and $\mathrm{Mg}$. The content of $\mathrm{Al}, \mathrm{Fe}$ and $\mathrm{K}$ is about three times higher in the marl than in the chalk.
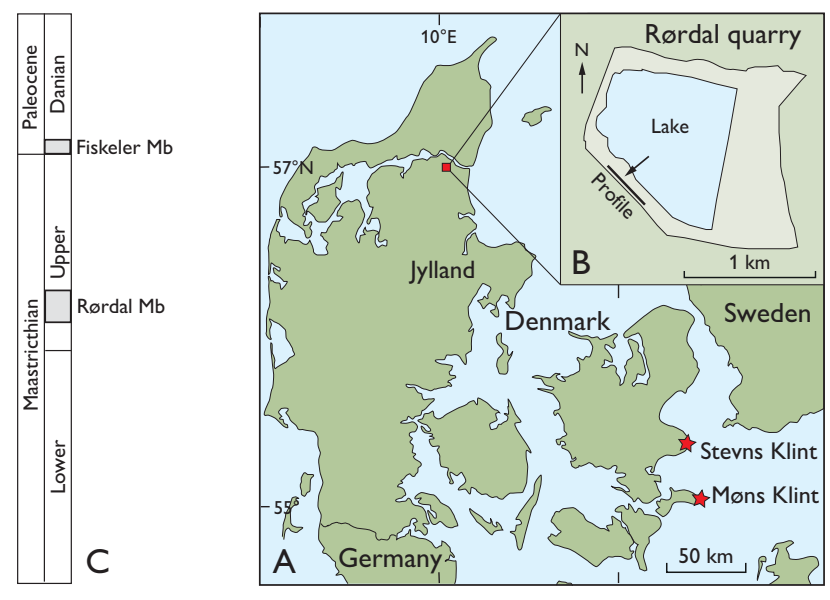

Fig. 1. A: Location of the Rørdal quarry, Stevns Klint and Møns Klint in Denmark. B: Map of the Rørdal quarry with the profile where the samples were collected. C: Stratigraphic section with Rørdal and Fiskeler members. 


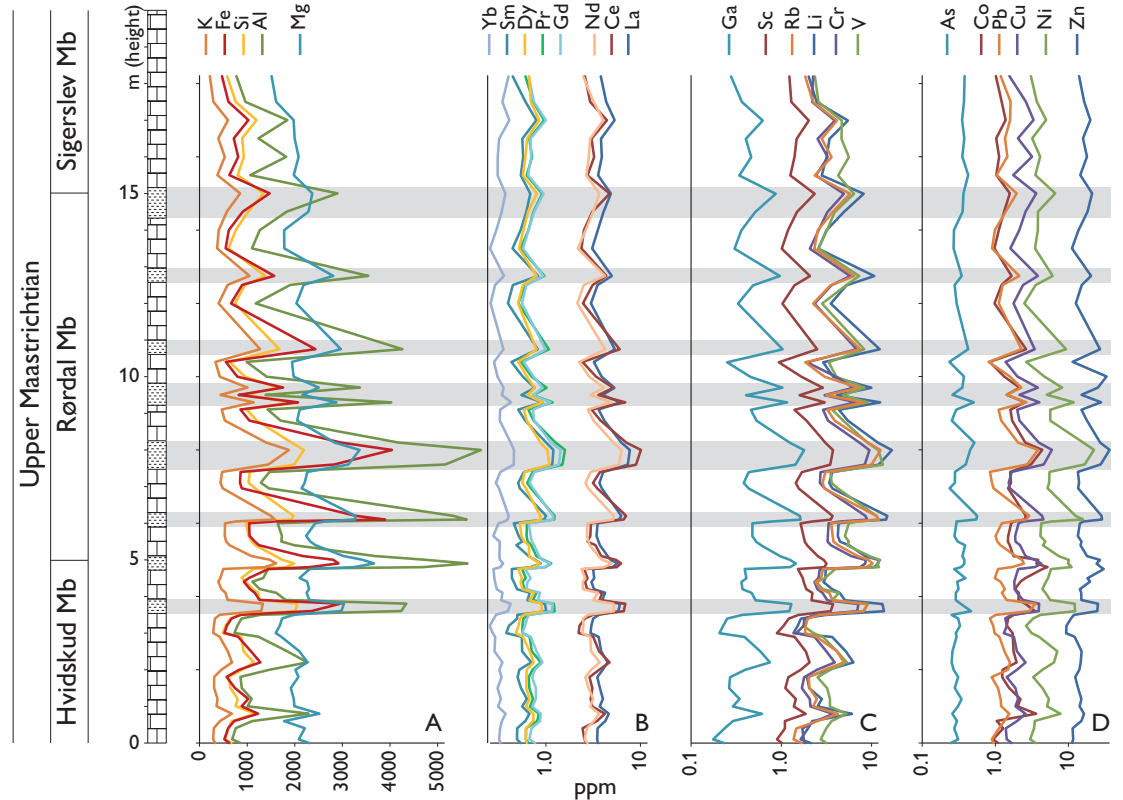

Fig. 2. Chemical profiles through the Rørdal Member including the uppermost part of the Hvidskud Member and the lowermost part of the Sigerslev Member. Marly layers are shown as grey shaded bands. A: Major and minor elements. B: REE; logarithmic scale. C: Lithophile trace elements; logarithmic scale. D: Chalcophile elements with $\mathrm{Ni}$ and $\mathrm{Co}$; logarithmic scale. Stratigraphy from Surlyk $e t$ al. (2013).
The concentration of many trace elements, including the rare-earth elements (REE), is also elevated in the marly layers (Fig. 2B). If all REE were located in clay the increase would be three times higher, as is the case with $\mathrm{Al}, \mathrm{K}$ and $\mathrm{Fe}$, but the content of REE in the marl is 'only' 1.5 times higher than in the chalk. This suggests that although the REE concentration is higher in the clay than in the chalk a substantial fraction of the REEs is located in the carbonate component of both chalk and marl. Lanthanum and Nd follow parallel tracks (Fig. 2B), whereas Ce crosses both tracks with relatively high Ce in the marl. Light REE (La, $\mathrm{Ce}, \mathrm{Pr}, \mathrm{Nd}$ and $\mathrm{Sm}$ ) are more abundant than heavy REE (Er, Tm, $\mathrm{Yb}$ and $\mathrm{Lu}$ ) in the marl compared to the chalk, which can also be seen as higher La/Lu ratios (Figs 3E, 4).

Lithophile elements such as Th, Cs, Rb, Be, Cr, Sc and $\mathrm{Li}$ increase in concentrations in the marl (of which $\mathrm{Rb}$ and $\mathrm{Li}$ are shown in Figure 2C) and are c. 2.5 to 3 times higher in the marl than in the chalk, similar to the behaviour of $\mathrm{Al}$ and $\mathrm{K}$. This suggests that these elements are almost entirely located in the clay. Chalcophile elements such as $\mathrm{Pb}$, As, $\mathrm{Zn}$ and $\mathrm{Cu}$ (Fig. 2D) are c. 1.5 times higher in the marl than in the chalk similar to the REE mentioned above.

The content of most elements in the succession varies with the clay content. However, this is not the case for $\mathrm{Nb}$, $\mathrm{Zr}, \mathrm{Mn}$ and Ti (Fig. 3A). Mica and clay commonly contain some $\mathrm{Ti}, \mathrm{Zr}$ and $\mathrm{Nb}$, elements that also occur in mafic volcanic material. These elements are difficult to leach out of minerals and generally follow clay and mica in sedimentary environments. If the clay was clastic or volcanogenic one would expect that the content of elements such as $\mathrm{Ti}$, $\mathrm{Zr}$ and $\mathrm{Nb}$ would be elevated in the marl. However, this is not the case, suggesting that a fraction of the clay may be of authigenic origin.

Manganese is probably hosted in the carbonate and its concentration is relatively stable throughout the analysed section. There is a decrease in the Ba content in the Rørdal Member (Fig. 3B) relative to the underlying Hvidskud Member with the lowest contents in its middle part. There is an increase in $\mathrm{Sr}$ content in the overlying Sigerslev Member. Jørgensen (1986) observed a similar increase in the Sr content in chalk from the North Sea Basin and this may be regional.

\section{Ce anomaly as a proxy for redox potential}

The REE commonly occur as cations with a valency of three and the different REE have similar geochemical behaviour in the sedimentary environment. However, one of the elements, $\mathrm{Ce}$, can also occur as $\mathrm{Ce}^{4+}$ with a very low solubility in marine environments as compared to $\mathrm{Ce}^{3+}$. Where no fractionation of Ce relative to the other REE has occurred, the distribution would be seen as a straight line on Fig. 3D. To quantify the fractionation of $\mathrm{Ce}$, the term $\mathrm{Ce}$ anomaly $\left(\mathrm{Ce} / \mathrm{Ce}^{*}\right)$ has been introduced; $\mathrm{Ce}$ is the measured cerium concentration and $\mathrm{Ce}^{*}$ is what the $\mathrm{Ce}$ content would have been without fractionation, based on the contents of $\mathrm{La}$ and $\mathrm{Nd}$. The Ce anomaly is calculated: $\mathrm{Ce} / \mathrm{Ce}^{*}=3 \mathrm{Ce}^{\mathrm{N}} /\left(2 \mathrm{La}^{\mathrm{N}}+\mathrm{Nd}^{\mathrm{N}}\right)$ where $\mathrm{REE}^{\mathrm{N}}$ is the measured concentration normalised relative to chondrite (Boynton 1984). In this paper a Ce anomaly is referred to as negative when $\mathrm{Ce}$ is depleted relative to the other REE and as positive if $\mathrm{Ce}$ is enriched relative to the other REE. In 
Fig. 3. Chemical profiles in the Rørdal Member. Same stratigraphy as Fig. 1. Marly layers are shown as grey shaded bands. A: $\mathrm{Nb}, \mathrm{Zr}$, $\mathrm{Rb}, \mathrm{Mn}$ and Ti; logarithmic scale. B: Ba. C: Sr. D: Ce anomaly. E: La/Lu ratio; logarithmic scale.

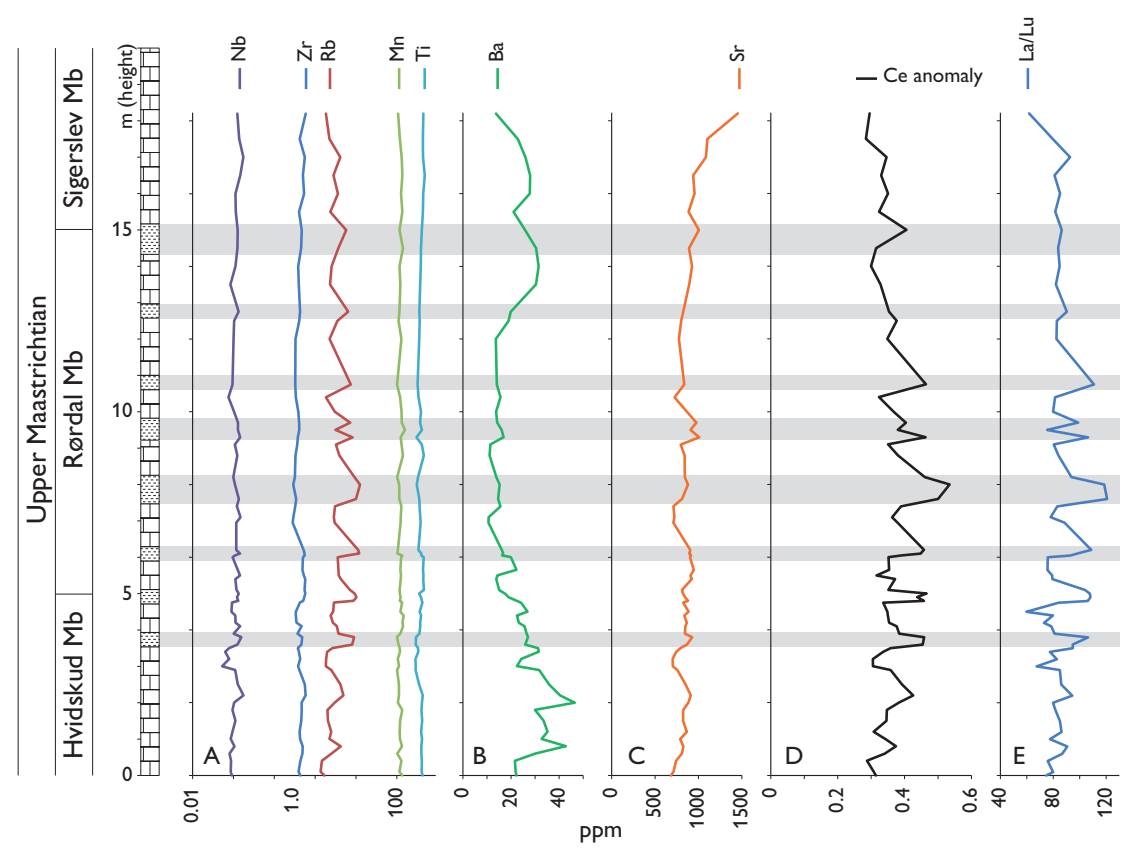

the modern marine environment, a negative Ce anomaly is indicative of oxic conditions (German \& Elderfield 1990) which, in turn, is caused by the low solubility of $\mathrm{Ce}^{4+}$ and low availability of $\mathrm{Ce}$. This feature offers the possibility to look into variations in the redox conditions during deposition of the chalk (Jeans et al. 2015). In Fig. 4 it can be seen that there is a negative Ce anomaly both in the chalk and in the marl in the Rørdal quarry as well as in the chalk and the fish-clay at Stevns. There is also a negative Eu anomaly which is probably caused by the source of the REE being slightly depleted in Eu (Frei \& Frei 2002). The negative Ce anomaly in the chalk at Stevns is more pronounced than in the chalk at Rørdal (Fig. 4) suggesting that the environment during deposition of the chalk at Stevns was more oxic than at Rørdal. The chalk at Stevns has a higher stratigraphic position (in the Sigerslev Member) and the change in the Ce anomaly with time could suggest that the oxygen availability in the chalk sea increased with time during the late Maastrichtian. Alternatively, this could suggest that the chalk at Stevns was deposited in a shallower sea.

The Ce concentration at Rørdal changes with lithology and stratigraphic position in the section (Fig. 3D); it is lower in the chalk than in the marl, indicating that the environment was more oxic in the chalk than in the marl. The REE (including $\mathrm{Ce}$ ) are located in the carbonate component as well as in the clay as mentioned above. Accordingly, the Ce anomaly reflects the combined effect of the composition of the seawater where the coccoliths and where the clay were formed. Surlyk et al. (2010) suggested that the clay in the Rørdal Member is derived from volcanic eruptions. Such clay, derived from alteration of volcanic glass, is likely to have an overall resemblance to the REE distribution in the source. However, the transformation from glass to clay in the marine environment could be the cause of the negative $\mathrm{Ce}$ anomaly found in the marl. The fish-clay at Stevns also has this negative Ce anomaly which is indicative of formation of clay in a marine environment (Kastner et al. 1984; Frei \& Frei 2002). The question is then whether the clay was (trans)formed from volcanic glass in the free water masses or in the seabed. The seabed is likely to have been less oxic than the free water mass, and formation of the clay in the seabed would explain the difference in the redox potential compared to the chalk formed in the free water mass. Finally, the composition of the clay minerals could have been modfied during diagenesis in the presence of organic material affecting the Ce anomaly.

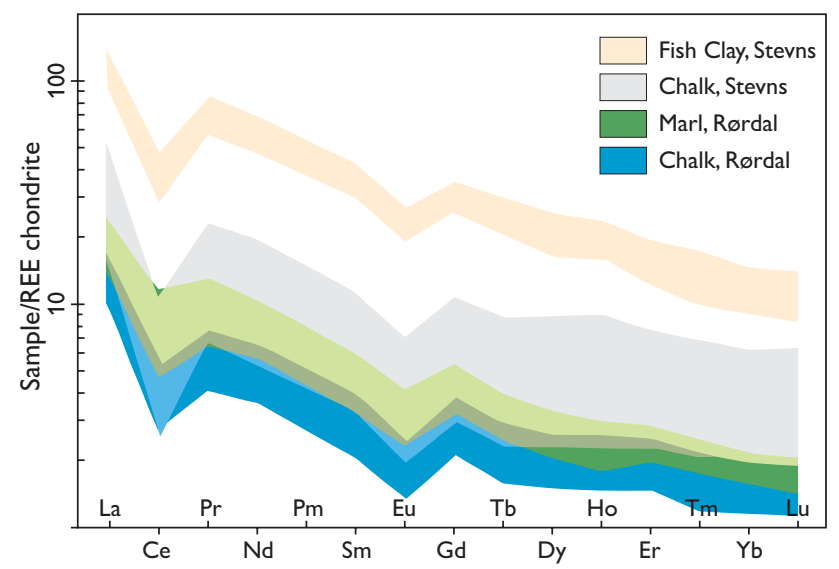

Fig. 4. Chondrite-normalised REE distribution patterns for the Rørdal samples compared with REE data from Stevns Klint (Frei \& Frei 2002). 


\section{Summary and outlook}

The chemical composition of the chalk-marl sequence at Rørdal in Jylland reflects the varying proportions of carbonate and clay. The content of major and minor elements such as $\mathrm{Si}, \mathrm{Al}, \mathrm{Fe}$ and $\mathrm{K}$ is proportional to the clay content, with a threefold increase in the marly layers relative to the chalk layers. It is suggested that these elements are located in clay minerals together with lithophile trace elements such as $\mathrm{Li}$, $\mathrm{Ga}, \mathrm{Rb}, \mathrm{Cs}$ and Th which likewise increase threefold in the clay relative to the chalk. Other elements such as $\mathrm{Pb}, \mathrm{As}, \mathrm{Zn}$ and $\mathrm{Cu}$ and the REE are found in $c .1 .5$ times higher concentrations in the marl, and these elements are located both in the clay and the carbonate component of the succession. The clay has a light REE enrichment compared to the chalk.

Formation of the clay as authigenic minerals may explain why large ion lithophile elements such as $\mathrm{Zr}$ and $\mathrm{Nb}$, as well as $\mathrm{Ti}$, are not incorporated in the clay. The content of $\mathrm{Ba}$ in the Rørdal Member is low relative to the under- and overlying strata, and the deposition of $\mathrm{Ba}$ could be tested as a chemo-stratigraphic marker and environmental proxy.

The REE distribution shows a negative Ce anomaly both in the chalk and in the marl, suggesting that the environment was oxic throughout the deposition, and as the Ce anomaly is more pronounced in the chalk, the environment was more oxic where the carbonate was formed than in the clay. This observation matches the observation that there is higher species diversity and density in the chalk than in the marl (Lauridsen \& Surlyk 2008). If the clay and the carbonate were formed in the same water mass, the observed alternating redox level would be indicative of changing conditions in the sea. However, if the main part of the clay was formed in the seabed as authigenic minerals or was affected by diagenesis, then the alternating redox levels indicated by the Ce anomaly reflects changes in redox conditions at or in the seabed. The Ce anomaly in chalk from Stevns is larger than in chalk from Rørdal, suggesting that the environment was more oxic in the chalk sea towards the end of the Maastrichtian. These differences could be related to changes in temperature over time. A recent study by Thibault et al. (2016) suggests a global cooling with superimposed cool/warm fluctuations in the last $8 \mathrm{Ma}$ of the Maastrichtian including e.g. the Rørdal and Sigerslev Members. It is suggested that the Ce anomaly can be used as a palaeo-redox indicator or proxy to compare environments across chalk basins. In this context it is interesting to analyse both carbonate and clay components from the marl.

\section{Acknowledgement}

We wish to thank Lars Stemmerik for constructive comments on earlier versions of the manuscript.

\section{References}

Boynton, W.V. 1984: Cosmochemistry of the rare earth elements: meteorite studies. In: Henderson, P. (ed.): Rare earth element geochemistry, 63-114. Amsterdam: Elsevier.

Frei, R. \& Frei, K.M. 2002: A multi-isotopic and trace element investigation of the Cretaceous-Tertiary boundary layer at Stevens Klint, Denmark - inferences for the origin and nature of siderophile and lithophile element geochemical anomalies. Earth and Planetary Science Letters 203, 691-708.

German, C.R \& Elderfield, H. 1990: Application of the Ce anomaly as a paleoredox indicator: the ground rules. Paleoceanography $\mathbf{5}$, 823-833.

Jeans, C.V., Wray, D.S. \& Williams, C.T. 2015: Redox conditions in the Late Cretaceous Chalk Sea: the possible use of cerium anomalies as palaeoredox indicators in the Cenomanian and Turonian chalk of England. Acta Geologica Polonica 65, 345-366.

Jørgensen, N.O. 1986: Geochemistry, diagenesis and nannofacies of chalk in the North Sea Central Graben. Sedimentary Geology 48, 267-294.

Kastner, M., Asaro, F., Michel, H.V., Alvarez, W. \& Alvarez, L.W. 1984: The precursor of the Cretaceous-Tertiary boundary clays at Stevns Klint, Denmark, and DSDP Hole 465A. Science 226 (4671), 137-143.

Larsen, L M., Heaman, L.M., Creaser, R.A., Duncan, R.A., Frei, R. \& Hutchinson, M. 2009: Tectonomagmatic events during stretching and basin formation in the Labrador Sea and the Davis Strait: evidence from age and composition of Mesozoic to Palaeogene dyke swarms in West Greenland, Journal of the Geologicla Society (London) 166, 999-1012.

Lauridsen, B.W. \& Surlyk, F. 2008: Benthic faunal response to late Maastrichtian chalk-marl cyclicity at Rørdal, Denmark. Palaeogeography, Palaeoclimatology, Palaeoecology 269, 38-53.

Lauridsen, B.W., Surlyk, F. \& Bromley, R.G. 2011: Trace fossils of a cyclic chalk-marl succession; the upper Maastrichtian Rørdal Member, Denmark. Cretaceous Research 32, 194-202.

Surlyk, F., Stemmerik, L., Ahlborn, M., Harlou, R., Lauridsen, B.W., Rasmussen, S.L., Schovsbo, N., Sheldon, E. \& Thibault, N.R. 2010: The cyclic Rørdal Member - a new lithostratigraphic unit of chronostratigraphic and palaeoclimatic importance in the upper Maastrichtian of Denmark. Bulletin of the Geological Society of Denmark 58, 89-98.

Surlyk, F., Rasmussen, S.L., Boussaha, M., Schiøler, P., Schovsbo, N.H., Sheldon, E., Stemmerik, L. \& Thibault, N.R. 2013: Upper Campanian-Maastrichtian holostratigraphy of the eastern Danish Basin. Cretaceous Research 46, 232-256.

Thibault, N., Harlou, R., Schovsbo, N.H., Stemmerik, L., Surlyk, F. 2016: Late Cretaceous (late Campanian-Maastrichtian) sea surface temperature record of the Boreal Chalk Sea. Climate of the Past 12, 429-438.

\footnotetext{
Authors' address

Geological Survey of Denmark and Greenland, Øster Voldgade 10,DK-1350 Copenhagen K, Denmark, E-mail: ckn@geus.dk
} 